\title{
Study on the Influencing Factors of Haze Pollution from the Perspective of Space--Taking the Yangtze River Delta Urban Agglomeration as an Example
}

\author{
Ting Gan ${ }^{1}$, Wei Liang ${ }^{1, *}$ \\ ${ }^{1}$ Business School, University of Jinan, Jinan 250002, China
}

\begin{abstract}
In recent years, haze frequently occurs in the Yangtze river delta region. In order to explore the influencing factors of haze pollution, the paper uses panel data from 2006 to 2016 and spatial lag model to explore the influencing factors of $\mathrm{PM}_{2.5}$. The results show that there is an inverted $\mathrm{u}$-shaped relationship between haze pollution and economic development. The increase of the tertiary industry and the progress of science and technology can improve haze pollution, while the increase of foreign direct investment and the continuous expansion of population will exert pressure on the environment. Finally,according to the research results of this paper, the corresponding policies are proposed.
\end{abstract}

\section{Introduction}

Since 2013, the smoggy weather in various cities across the country has caused frequent public and government concerns. So far, many cities have become key targets of pollution control, including the Yangtze river delta where smog has become increasingly severe. The regions consist of 26 cities in four provinces of Shanghai, Jiangsu, Zhejiang and Anhui. It is a key area for China's economic development. The region brings together heavily polluting industries such as steel, chemicals and electronics. The rapid development of heavy industry leads to energy resources are constantly being consumed. In the process of development, the extensive development model that emphasizes economic development and neglects the ecological environment restricts the low-carbon development of the Yangtze River region. The main particulate pollutants of smog are $\mathrm{PM}_{10}$ and $\mathrm{PM}_{2.5}$, which seriously threaten people's health.In 2016, China experienced eight large-scale and prolonged haze days, among which the urban agglomeration in the Yangtze river economic belt has serious pollution problems.According to the 2017 Bulletin on the State of Ecological Environment, the number of excellent days in the region decreased by $1.3 \%$ compared with 2016 , with the average number of days exceeding the standard being $25.2 \%$ of the total number of days, and the pollutants in the exceeded days were $\mathrm{PM}_{2.5}$ and $\mathrm{PM}_{10}$ is the main.

Haze pollution has become a bottleneck in the development of the Yangtze River Delta urban agglomeration, which not only affects the normal life and health of the people, but also affects social and economic development. The report of the 19th National Congress pointed out that we must win the battle against blue sky and take the green development path. The State Council pointed out in the "Guiding Opinions" on the Yangtze River Economic Belt that it should strengthen air pollution prevention and control and improve the straw burning mechanism. Therefore, exploring the current situation of smog pollution affecting the Yangtze River Delta urban agglomeration is of great significance to the government's rational formulation of atmospheric protection policies and the promotion of economic development.

\section{Literature review}

At present, scholars' research on smog pollution mainly focuses on meteorological, geographical and chemical factors, but the increase of haze pollution is also caused by human factors such as extensive production methods and unreasonable industrial structure. Exploring the relationship between economic development and haze pollution has always been a hot topic for scholars. The environmental Kuznets curve (EKC) proposed by Grossman and Krueger([1])has been recognized by most scholars. Environmental EKC curve refers to an inverted $\mathrm{u}$-shaped relationship between environment and economy. Some scholars have different views on this curve, and have proposed U-shaped and inverted N-type respectively. Some scholars believe that there is no obvious linear relationship between the two.

For the study of smog pollution, most scholars currently use $\mathrm{CO}_{2}, \mathrm{SO}_{2}$, industrial waste, $\mathrm{PM}_{10}$, etc. as routine indicators for pollution research. Wang and $\mathrm{Liu}([2])$ used the carbon dioxide emissions as a measure to support the EKC assumptions. Peng and Bao([3]) used sulfur dioxide and industrial wastewater discharge as

\footnotetext{
* Corresponding author: 1w99@foxmail.com (W. Liang)
} 
representative indicators for studying air pollution. Xie([4]) considered the diversity of pollutants in the selection of pollutants and used three industrial wastes as pollutants. The results showed that new-type urbanization was a decisive factor affecting urban environmental quality. In addition, a part of the literature studies the relationship and impact of $\mathrm{PM}_{10}$ and economic development. As a new term, smog has only received government attention in recent years. In 2013, the country began to set up a site to monitor $\mathrm{PM}_{2.5}$. Although $\mathrm{PM}_{2.5}$ is representative, data acquisition is limited. There have been few studies on smog pollution, and some studies have used data from recent years.

Zhou and Fan([5]) studied the relationship between social and economic factors and pollutants in 339 prefecture-level cities using sectional data from 2012, and the results showed that different environmental pollution sources have different degrees of social and economic influence on them. Guo([6]) used the DEA method to study the economic and environmental efficiency of 11 cities in the Yangtze River Economic Belt. The research shows that the environmental efficiency of the upper and lower reaches of the Yangtze River Economic Belt is very different. Ren([7]) used per capita GDP and industrial added value as threshold variables, and used the threshold model to study the relationship between environment and economy in the Yangtze River Economic Belt. The results show that the impact of the economy on the environment is a single threshold effect. At present, there are some shortcomings in the literature. (1) In the selection of indicators, $\mathrm{PM}_{2.5}$ is rarely selected due to data acquisition difficulties. (2) Most of the research is still at the provincial level to explore the overall smog pollution in the country. There are few studies on the Yangtze River Delta. (3) Most of the studies used traditional measurement methods, ignoring the diffusivity of the smog pollution space. In summary, this paper uses the data of the Yangtze River Delta urban agglomeration from 2006 to 2016, using $\mathrm{PM}_{2.5}$ as a measure of smog pollution, using the inverse distance matrix and the spatial error model to explore the factors affecting haze pollution.

\section{Empirical analysis}

\subsection{Formatting the text}

Because of the characteristics of the haze, it is necessary to determine whether the pollution in the area is spatially correlated. This problem can be tested by the global and local Moran's I indices. The global Moran index test formula is:

$$
I=\frac{\sum_{i=1}^{n} \sum_{j=1}^{n} w_{i j}\left(x_{i}-\bar{x}\right)\left(x_{j}-\bar{x}\right)}{S^{2} \sum_{i=1}^{n} \sum_{j=1}^{n} w_{i j}}
$$

When the value of $I$ is greater than 0 and the closer to 1 , the smog pollution is spatially positively correlated. Conversely, when the $I$ value is less than 0 and closer to
-1 , the smog pollution is spatially negatively correlated. $W_{\mathrm{ij}}$ is a spatial weight matrix. In this paper, the inverse distance matrix is used. According to the first law of geography, the smog pollution will decrease with the increase of the matrix.

This paper uses stata14.0 to calculate the global Moran index. It can be seen from the research results that the global Moran I in 2006-2016 is all greater than 0, indicating that the haze pollution is spatially positively correlated.

In order to further observe whether there is agglomeration in the space of the Yangtze River Delta urban agglomeration, this paper uses the local Moran I index test. Due to space limitations, this article no longer shows partial LISA maps. From the test results, the I value of the region is greater than 0 , and cities are basically located in the first and third quadrants, indicating that the haze pollution is spatially agglomerated by $\mathrm{H}-\mathrm{H}$ and L-L.

\subsection{Analysis of results}

In order to explore the socio-economic factors affecting smog pollution, this paper selects the concentration of $\mathrm{PM}_{2.5}$ as a measure of haze pollution to indicate the explanatory variables.Since 2013 China has been monitoring $\mathrm{PM}_{2.5}$, data acquisition is difficult, so this article uses ArcGis10.0 processing satellite raster data to obtain $\mathrm{PM}_{2.5}$, this method can obtain more accurate results. This paper selects the regional GDP as the main explanatory variable, which is obtained according to the 2000 nominal GDP adjusted by the deflator, and selects the tertiary industry, the secondary industry, education expenditure, science and technology expenditure, foreign direct investment, population density and employees on the job,the average number of people is used as the control variable. The data source is the China Urban Statistical Yearbook from 2006 to 2016. The detailed description of the variables is shown in Table 1.

Table 1. The specific meaning of the variable.

\begin{tabular}{|c|c|}
\hline Name & Index \\
\hline $\ln 1$ & GDP \\
\hline $\operatorname{lnsc}$ & $\begin{array}{c}\text { The proportion of GDP in the tertiary } \\
\text { industry }\end{array}$ \\
\hline $\operatorname{lnec}$ & $\begin{array}{c}\text { The proportion of GDP in the secondary } \\
\text { industry }\end{array}$ \\
\hline lne & Educational expenditure \\
\hline $\operatorname{lns}$ & Technology expenditure \\
\hline $\operatorname{lnf}$ & Actual use of foreign capital \\
\hline $\operatorname{lnrk}$ & The population density \\
\hline $\ln z$ & Average number of employees on the job \\
\hline
\end{tabular}

It can be seen that the haze has a spatial spillover effect according to the correlation test of smog pollution. Therefore, the traditional measurement method is no longer applicable. This paper uses the spatial measurement method to build a model, draws on the environmental EKC curve, and selects the primary and secondary of GDP as the core explanatory variables. 
Spatial Lag Model:

$$
\begin{gathered}
\ln P M_{i t}=\beta_{0}+\rho \times W \ln P M+\beta_{1} \times \ln r 1+\beta_{2} \times \\
\ln r 2+\beta_{3} \times \ln s c+\beta_{4} \times \ln e c+\beta_{5} \times \ln e+ \\
\beta_{6} \times \ln s+\beta_{7} \times \ln f+\beta_{8} \times \ln r k+\beta_{9} \times \\
\ln z+\delta_{i}+\mu_{i}+\varepsilon_{i t} \\
\varepsilon_{i t} \sim N\left(0, \sigma_{i t}^{2} I_{n}\right)
\end{gathered}
$$

Spatial Error Model:

$$
\begin{gathered}
\ln P M_{i t}=\beta_{0}+\beta_{1} \times \ln r 1+\beta_{2} \times \ln r 2+\beta_{3} \times \ln s c \\
+\beta_{4} \times \ln e c+\beta_{5} \times \ln e+\beta_{6} \times \ln s+\beta_{7} \times \\
\ln f+\beta_{8} \times \ln r k+\beta_{9} \times \ln z+\delta_{i}+\mu_{i}+\varepsilon_{i t} \\
\varepsilon_{i t}=\lambda W_{i t}+\varphi_{i t} \quad \varphi_{i t} \sim N\left(0, \sigma_{i t}^{2} I_{n}\right)
\end{gathered}
$$

\begin{tabular}{|c|c|c|c|c|}
\hline & \multicolumn{2}{|c|}{ SEM } & \multicolumn{2}{|c|}{ SLM } \\
\hline & $\mathrm{FE}$ & $\mathrm{RE}$ & FE & $\mathrm{RE}$ \\
\hline $\ln 1$ & $0.538 * * *$ & -0.465 & $0.453 * * *$ & -0.427 \\
\hline $\ln r 2$ & $-0.0191 * *$ & 0.0167 & $-0.0169 * *$ & 0.0150 \\
\hline $\operatorname{lnsc}$ & $-0.364 * * *$ & $-0.172 * *$ & $-0.356 * * *$ & $-0.144 *$ \\
\hline $\operatorname{lnec}$ & -0.0565 & $-0.106^{*}$ & -0.0297 & -0.107 \\
\hline lne & 0.0153 & -0.0105 & 0.0155 & -0.0116 \\
\hline $\operatorname{lns}$ & $-0.115 * * *$ & 0.00109 & $-0.122 * * *$ & 0.00425 \\
\hline $\operatorname{lnf}$ & $0.190 * * *$ & -0.00034 & $0.186^{* * *}$ & 0.00121 \\
\hline lnrk & $0.188 * * *$ & -0.00870 & $0.186^{* * *}$ & -0.00621 \\
\hline $\ln z$ & -0.00891 & 0.00474 & 0.00673 & 0.0105 \\
\hline$\lambda$ & $0.765 * * *$ & $0.878 * * *$ & & \\
\hline$\rho$ & & & $0.822 * * *$ & $0.872 * * *$ \\
\hline AIC & -208.668 & -692.928 & -207.740 & -667.069 \\
\hline $\mathrm{BIC}$ & -168.452 & -645.400 & -101.717 & -553.733 \\
\hline $\begin{array}{l}\text { Log- } \\
\text { likeli } \\
\text { hood }\end{array}$ & 115.3341 & 359.4639 & 132.8702 & 364.5344 \\
\hline $\mathrm{N}$ & 286 & 286 & 286 & 286 \\
\hline
\end{tabular}

In this paper, the empirical results of Spatial Error model and Spatial Lag model are obtained by stata14.0, as shown in Table 2. The purpose of the inquiry is to further explore the differences between the Yangtze River Delta urban agglomeration under different models.

Table 2.the results of factors affecting smog pollution.

It can be seen from the table that in these two models, the fixed effect is better than the random effect, and most of the indicators pass the $10 \%$ significance test. According to the Akaike information criterion, the model with large AIC and BIC values is selected, so the fixed effect of the spatial lag model should be optimal.

It can be seen from the results that the coefficient in the spatial lag model is positive and significant at the level of $1 \%$, which is consistent with the correlation test result, and the smog pollution is spatially positively correlated. The primary term of the variable GDP is passed the significance test at the $1 \%$ level and the coefficient is positive. The quadratic term passes the significance test at the $5 \%$ level and the coefficient is negative. The economic development and the smog pollution are reversed. U-shaped relationship. With the economic development in the Yangtze River Delta region, smog is a trend of rising first and then falling.It's the reason the traditional development model that values economic development and neglects the environment has brought about serious pollution. The government and the public have paid attention to environmental problems. It's requires that enterprises pay attention to environmental protection while developing the economy and strengthen their environmental awareness. As a result, pollution has turned inflection points and began to decline.

The coefficient of the tertiary industry and science expenditure is negative and passes the significance test at the level of $1 \%$, which means that when the two indicators increase by $1 \%$, the haze pollution in the region drops by 0.356 and 0.122 respectively. The fdi and the population density coefficient are positive and both pass the significance test at the level of $1 \%$, indicating that the level of openness is positively affected by smog pollution, the foreign direct investment amount increases by $1 \%$, and the smog pollution increases by 0.186 . The reason why the increase of FDI will aggravate haze pollution is that some developed countries transfer some pollution-intensive enterprises to this region, while the triangle region relaxes regulations to attract foreign investment and lowers the standards of foreign enterprises entering this region. For every $1 \%$ increase in population density, the dependent variable will increase by 0.186 , indicating that the increasing population size has put pressure on the environment.

\section{Conclusions and recommendations}

In order to further study the socio-economic factors affecting smog pollution in the Yangtze River Delta, this paper uses panel data from 2006 to 2016 to measure the $\mathrm{PM}_{2.5}$ smog pollution using the fixed effect of the spatial lag model. The results show that the smog pollution has spatial spillover effect, and there are high-high and lowlow agglomeration.There is an inverted U-type relationship between economic development and smog pollution; the impact of tertiary industry and technology spending on smog pollution is reversed. The increase in foreign investment and the expansion of the population will increase the smog pollution in the Yangtze River Delta.

Based on the results of the study, the following measures can be taken:

(1) The smog pollution in the Yangtze River Delta region has a spatial diffusion effect. It is difficult for any city to independently manage the smog problem. Therefore, it is necessary to strengthen the awareness of cooperation among local governments, jointly manage environmental issues, and formulate atmospheric protection policies. 
(2) Optimizing the industrial structure and increasing investment in science and technology. It can be seen from the results that the increase of the tertiary industry can improve the haze weather. Therefore, it is necessary to eliminate the traditional industries with high energy consumption and high pollution, increasing the tertiary industry of green energy technology, and realize the industrial transformation of the Yangtze River Delta urban agglomeration. At the same time, the government should increase investment in science and technology, increase scientific and technological innovation, encourage enterprises to develop and create new green environmental protection technologies, optimize and upgrade traditional high energy-consuming technologies, and improve the efficiency of resource utilization.

(3) Raising the threshold for foreign companies to enter the region. The region has loosened its control and led to the entry of some highly polluting foreign-invested enterprises for attracting more foreign investment, which has increased environmental pollution in the region. Therefore, local governments should raise the entry standards for foreign investment and strengthen the screening of foreign companies.

\section{Acknowledgments}

Thanks to my mentor - Professor Liang. When I was studying the paper, when I encountered problems and confusion, my teacher would help me clarify my thoughts and put forward some ideas and suggestions, so that I could make a breakthrough. During the period of I write a paper, my teacher carefully and patiently revised my paper, helped me find research materials, encouraged me to publish core journals, and suggested that I learn more about spatial measurement.In addition, I would like to thank my classmates and sisters for their relationship and encouragement in my daily life and study, and help me when I am in trouble. at the same time, This work was financially supported by the National Social Science Fund Annual Program of China (Grant No. 18BGL275). The authors would like to thank the editor of this journal and the reviewers for their detailed and helpful comments.

\section{References}

1. Grossman, G. M. , \& Krueger, A. B. (1991). Environmental impacts of a north american free trade agreement. Social Science Electronic Publishing, 8(2), 223-250.

2. Wang, S. , \& Liu, X. (2017). China's city-level energy-related co2, emissions: spatiotemporal patterns and driving forces. Applied Energy, 200, 204-214.

3. Peng, S. , \& Bao, Q. (2006). Economic growth and environmental pollution: China test of environmental kuznets curve hypothesis. Research on Financial and Economic Issues, 08 , 3-17.

4. Xie, R., Chen ,Y. , \& Han, F. (2018). Impact of new-type urbanization on urban ecological environment quality and spatial-temporal effect . Business Review.

5. Zhou, K. , \& Fan, J. (2016). Regional differences of environmental pollution sources in China and their socio-economic influencing factors -- an empirical analysis based on sectional data of 339 prefecturelevel administrative units. Acta Geographica Sinica

6. Guo, F. (2017). Evaluation of environmental efficiency in the Yangtze river economic belt and analysis of influencing factors. Journal of Hebei GEO University, (4), 30-36.

7. Ren, X. (2018). Analysis of threshold effect of economic growth on haze pollution in the Yangtze river economic belt. Statistics \& Decision, (20)34. 